\title{
Relational Leadership, Storytelling and Narratives: The Practices of UK Local Government Chief Executives
}

\section{Introduction: Leadership, Narratives and Stories}

In this article we examine the relational narrative and storytelling practices of a group of senior UK public administrators, local government chief executives. In doing so we respond to calls for scholarship exploring the distinctive settings of leadership action with an explicit focus on the detailed dynamics of leadership (Nelson and Svara 2013; Van Wart 2013). We engage with the narrative turn in public administration (Ospina and Dodge 2005) and with the relationality conversation in leadership studies. The contribution to theory is to provide insights into the ways in which stories and narratives are pivotal in the day-to-day, relational practices of public administration leaders. In this way we generate empirical knowledge about the collective dimensions of leadership.

Leadership is at the heart of the public administration mission. However, in their millennial review Kellerman and Webster found the literature on public leadership to be "meager" $(2001,485)$. Van Wart's described it as "muted and underdeveloped" (2003, 223), and Trottier, Van Wart and Wang (2008) contrasted advances in mainstream organizational literatures, featuring increasingly sophisticated ideas about leadership, with less mature work in the public administration sphere. Such critiques have provided impetus to leadership research seeking to understand the specificities of goals, culture, context and practice within public sector organizations.

Our focus is worthwhile for several reasons. Storytelling represents a topic of great contemporary appeal to practitioners and therefore may help to overcome what Van Wart 
(2013) identifies as the dangers of obscurity in leadership theory. $\mathrm{Ng}$ and De Cock (2002) suggest that grounding research in the living narratives of organizations may increase the relevance of scholarly knowledge. Furthermore, our work promotes a "connectedness" (Raadschelders and Lee 2011; Stillman 2011) of value to PAR readers, editors and contributors - connecting our inquiry with frontline storytelling practices; connecting an academic and a practitioner as co-researchers; and connecting concepts and concerns from different fields (including public administration, organization studies, and narrative inquiry) of social science.

Yukl provides perhaps the most oft-quoted definition of leadership as "a process of influencing and teaching others to understand why and how certain activities and goals need to be accomplished. As such, it constitutes a process of facilitating individual and collective efforts to learn and accomplish shared goals in organizations" (2006, 579). Central to Yukl's conceptualization of leadership is the idea of the creation of shared understandings and common goals - a process of influencing, of shaping appreciations of context, purpose, or priorities. Likewise, Kouzes and Posner describe leadership as "the art of mobilizing others to want to struggle for shared aspiration" $(2002,24)$. Moore (2010) emphasizes the role of public administration pursuing an aspiration of public value in relation to common good. As Wright, Moynihan and Pandey point out, "[T] he inspirational power of public missions is not a given; it needs to be cultivated" $(2012,212)$. In other words public administration leaders must tap into the motivating power of worthwhile organizational goals “ “. by infusing jobs with meaning, and highlighting and rewarding public service values" (Perry and Hondeghem 2008, 309).

Fairhurst and Uhl-Bien (2012) highlight the relationality of leadership - how leaders and followers co-create meaning through interconnected relationships in highly interactive contexts. One of the ways in which these shared meanings are created in organizations is 
through narratives or stories which make sense of complexity and change. As Sternberg describes, creative leaders generate stories that "serve as a focal point for followers who are trying to understand the leaders' goals" $(2008,360)$. Narrative practices are therefore important to organizational adaption.

In this article we are interested in exploring one of the golden threads which runs through these definitions - the importance of influencing - and to do so we examine the ways in which leaders use narratives and stories to influence understanding and action in organizations. Examining practices through a lens of relationality moves the analysis beyond the notion of the 'hero leader' and instead enables us to understand the ways in which the everyday dilemmas of organizing are inescapably collective. This idea is powerful. It points us towards appreciating the ways in which public organizations are fuelled by stories and narratives which offer compelling accounts of the past, the present and the future - the very stuff of public leadership. Our analysis suggests the ways in which these provide a basis for mediating the collective, relational action of organizational life.

\section{Narratives and Stories in Public Administration Scholarship \&}

\section{Organization Studies}

In the last thirty years there has been "explosion of interest in narrative" (Herman 2007, 4).

This interest has travelled across disciplinary boundaries, representing an interpretive turn in the social sciences (Rabinow and Sullivan 1987), and a related narrative turn in organization studies. This turn encompasses an interest in knowledge, sense making, leadership and change, and research which explores what David Boje (1991) calls storytelling organizations.

The earliest uses of narrative approaches in organization studies were as recent as the 1970s (e.g. Clark 1972; Mitroff and Kilmann 1975). Partly fuelled by an interest in organizational culture and the rise of social constructivist approaches to understanding organizational life, 
researchers have developed an interest in how stories represent a means through which people generate knowledge at work. In this way, Brown, Gabriel and Gherardi (2009) remind us that stories are "deeply implicated in all aspects of organizational life and scholarship" (2009). In organization and management studies the role of narratives and stories is increasingly accepted as a fertile basis for understanding organizational life (Maclean et al. 2013; Boje 2008; Brown et al. 2008; Czarniawska 1998; Gabriel 2004; Rhodes and Brown 2005). A prominent strand of narrative research has been the role of stories in managing cultural change in organizations (Feldman 1990; McConkie and Boss 1986; Wilkins 1984). As Rhodes and Brown suggest, the power of stories stems from their potential to, "produce liminal conditions between current realities and future possibilities... helping people envision potential future realities from creative interpretations of the past" $(2005,173)$. Scholarship on organizational learning has also displayed a particular interest in stories (Taylor et al. 2002; Vance 1991), exploring their role in improving practices, or in enabling managers to connect to competing narratives in their organizations, or to learn from new perspectives on established truths, stale practices or wicked problems (Gold 1997; Mitroff and Kilmann 1975).

In public administration scholarship, the role of narratives and stories - as an interpretive methodology and as a significant aspect of public administrators' practice - has not yet succeeded in becoming front and center of scholarly attention. The lineage of narrative analysis in public administration can be traced back at least as far as Waldo (1968) who explored "administrative novels" of the 1950s and 1960s, centering on contemporary issues relevant to public administrators. Yet interest in stories and narratives in our field has been sporadic. Borins (2011) observed that "Though the use of narrative has become widespread through many disciplines, it has yet to establish a strong footing in public administration." 
That said, there have been some shining examples showing the promise of this scholarly focus. Hummel's (1991) study of practitioners was one of the first to look at the "stories managers tell" to each other and to explain "why they are valid as science". Hummel situated his work within Mintzberg's observations about managers' preferences for verbal and faceto-face channels of communication, and Kanter's (1977) insight that credibility and influence (achieved through face-to-face communication) is more critical than technical business knowledge. Subsequently our field has been enriched by scholars who advocate the importance of narrative approaches for the study of public administration and policy (Feldman et al. 2004; Fischer 2003; Hampton 2009; Lejano and Leong 2012; Skoldberg 1994). In Tales of the State Schram and Neisser (1997) explored local bureaucratic narratives within state organizations, set alongside the wider narratives of American national politics. Maynard-Moody and Musheno also brought us closer to practice through engaging with the narratives of street-level bureaucrats, urging scholars "to take stories and storytelling seriously rather than viewing them as mere diversions from work" $(2003,161)$. Feldman et al. argued that "Stories are useful to both participants and observers of organizations because they are a basic tool that individuals use to communicate and create understanding with other people and for themselves" $(2004,147)$. More broadly, Bevir has championed the importance of storytelling in governance and the idea that, "Public administration is less about finding formal connections, than about telling stories about beliefs, actions, practices, and their contexts" (2011, 190). In PAR, Wagenaar (2004) and Ospina and Dodge (2005) have been important figures in encouraging a focus on narrative as a valuable means of appreciating what "public administrators actually do".

This article seeks to build on this emerging scholarship by exploring the storytelling and narrative practices of a body of senior public administrators, UK local government chief executives. We provide an analysis of how stories and narratives are used to enact leadership 
in complex environments. In doing so we tease out the relationality inherent in these practices. This enterprise is important in order to appreciate the significance of narratives and storytelling in the exercise of leadership in public organizations, and to understand the collective aspects of leadership practices.

\section{Definitions of Stories and Narratives}

Barthes (1977) tells us that the narratives of the world are numberless and ever present. As Herman puts it, narrative is "a basic human strategy for coming to terms with time, process and change" $(2007,3)$. Ricoeur's definition of stories also emphasizes the connection between stories and change: "A story describes a sequence of actions or experiences done or undergone by a certain number of people... These people are presented either in situations that change or as reacting to such change. In turn, these changes reveal hidden aspects of the situation and the people involved, and engender a new predicament which calls for thought action, or both" $(1984,57)$. In other words, stories and narratives enable organizational actors to understand and formulate responses to new and unfolding situations. Generating shared understandings also connects with Weick's (1995) idea of "sense making" by managers and leaders - making sense of complexity through narrative techniques.

Though story and narrative are frequently taken to be synonyms, scholars often distinguish between the two, positioning stories as subordinate to narratives. Stories are set within larger, perhaps longstanding and overarching narratives. For example, there might be a narrative of organizational decline or failure and particular stories could be offered to illustrate or challenge those themes. Or, as for Feldman et al., "A change narrative might make the claim that empowerment is an engine of change. A story exemplifying this narrative would tell us how empowerment changed the actions of specific people in a specific time and place" 
$(2004,150)$. Our study is interested in both elements - particular uses of more structured stories, and also the wider narratives that play through organizations.

In this article, the focus includes, but is wider than, 'little d discourse' (Fairhurst 2007). We engage with the idea of discourse found in organization studies where it is a means to examine struggles of multiplicity and heterogeneity in organizational settings (Cooper \& Burrell 1988). We are interested in understanding the ways in which leaders shape narratives and utilize storytelling as part of their strategies of influencing this polyphony. This approach does not portray the protagonists as bureaucratic functionaries, pulling levers and operating the machinery of the state. Instead it situates public administration leaders within a web of narratives, through which, with their colleagues, they try to make sense of the confusion of organizational life, in order to better shape the future.

\section{Relationality}

A fruitful way to connect narrative and leadership is by engaging with the leadership studies discussion about 'relationality' (Denis et al. 2012; Uhl-Bien 2006) and its applications in public administration. Relationality scholarship highlights the importance of the collective dimensions of leadership, which have become so important given contemporary shifts in governance (Ospina and Foldy 2015). Uhl-Bien (2006) defines relational leadership as "a social influence process through which emergent coordination... and change (e.g., new values, attitudes, approaches, behaviors, and ideologies) are constructed and produced" (665). Leadership is accomplished through relational dynamics which play through an organization - people live and work in relation to others. Leadership action is inevitably embedded in complex relationships and collective sensemaking processes (Uhl-Bien 2006; Uhl-Bien and Ospina 2012). An interest in relationality also emerges from the practice turn in leadership studies (e.g. Alvesson \& Sveningsson 2003; Carroll, Levy, \& Richmond, 2008; Denis, 
Langley and Sergi 2012). Leadership is seen as located in practices and created in communications.

Its contribution is the insight that leadership is a social and collective process and that therefore relational practices need to be studied closely (Ospina and Foldy 2010). A key question in the relationality conversation is how can researchers best do so - how can they explore the relationship between colleagues in particular settings? Or, as Uhl-Bien and Ospina (2012, xiv) put it, “[H]ow do you get at... the 'space between'?” One answer to this is to see narrative as central to relationality, in that relationships are "inherently communicative" (Dachler 1992). This view directs attention to the communication practices, such as stories and narratives, through which "realities" are constructed. For example, the leadership enterprise of visioning the future is closely linked to stories, images and metaphors which can "draw in" others (Ospina and Foldy 2015, 497).

The relationality approach presents a post-heroic view of leadership (Crevani et al. 2010; Fletcher 2004; Spillane 2006). A relational lens avoids looking for traits, great persons, or even behavioural styles and instead focuses on how processes of leadership emerge in organizational and social settings. A relational view of leadership also chimes with Boje's definition of the storytelling organization as a "collective storytelling system in which the performance of stories is a key part of members' sensemaking” (Boje 1991, 106). In this way, leadership is accomplished collectively, within communities of practitioners, through local everyday interactions, and mediated by stories and narratives (Denis et al. 2012). This is the starting point for the analysis of our fieldwork.

\section{Context of the Study}

Local government in the UK accounts for around one quarter of public expenditure and is responsible for the delivery of key local services such as education, social care, public 
housing, and planning and transport. It is also the only directly-elected part of the public sector.

The office of chief executive evolved from that of town clerk, following the Bains Report (1972), which found that local government lacked management capacity, and the subsequent influence of new public management ideas which championed strategic management and leadership. The chief executive is a vital officer position focusing on translating the political will of local politicians (the elected members or Councillors) into tangible outcomes. It is best understood as a managerial and leadership role: leading programs of change in complex organizations of scale; setting tone, managing culture, and developing staff; and ensuring priorities are delivered. The job therefore combines aspects of leadership, strategy, communication and political management.

Councils are complex organizations, not least in relation to the range of front-line services for which they have responsibility, facing difficult decisions in the face of competing demands from different stakeholders, meeting statutory obligations in the midst of financial constraint, and addressing wicked social or economic issues. At the same time, the chief executive plays an important part in supporting the democratic role of councils. Chief executives work at the interface between professional officers and elected politicians, providing managerial leadership, advice to the politicians on strategy and policy, and acting in an executive capacity. In this way, they have responsibilities which their professional body, the Society of Local Authority Chief Executives (SOLACE), describes as entailing "speaking truth to power, protecting good governance and providing clear advice across the political spectrum" (SOLACE 2014, 3). As for Nalbandian et al.'s (2013) characterization of US city managers, chief executives operate at the nexus of what is politically acceptable and what is achievable organizationally. 
In this context, our article explores an overarching research question: What roles do stories and narratives play in the relational leadership practices of council chief executives? This includes attention to the how, the why, and the relationality, of storytelling and narrative practices.

\section{Research Methodology}

Our research design is rooted in a long-term engagement with local government chief executives. Our data exposure was enabled by our wider professional interactions with the network. In particular, Author 2's professional role as director of their professional association gave us an excellent opportunity to study leadership in complex situations. It facilitated our ability to engage with a busy and hard-to-access organizational elite. It also meant we were able to utilize elements of an ethnographic approach, drawing on access to the network as an "insider" researcher. Access to local knowledge and practices was important initially in shaping the focus of the study - what Miles, Huberman and Saldaña (2014) call anticipatory data condensation. It helped too in sense checking our interpretations with members of the network. We later examine two stories (e.g. 'Dinghy' and 'Naked') which Author 2 observed being used in practice. Author 2's status as a director of their professional association was useful in facilitating our ability to engage a busy and hard-to-access organizational elite, especially in the early stages of the study.

Our empirical method stems from work undertaken between 2008 and 2015 during which the authors jointly interviewed 80 local council chief executives in different types of UK council, including unitary authorities; county, metropolitan, and district councils; and London boroughs, and spanning different geographical locations across all four nations of the UK. Our approach to data exposure was not to produce a scientific claim to representativeness but to ensure that a plurality of organizations was included. Our meetings were purposeful 
conversations (Alvesson 2003) with research participants who we recognize as co-creating the encounter. We invited interviewees to respond to a range of story, narrative and leadership-themed questions about themselves, their council, their colleagues, their profession and their practices, such as 'Do you recognize storytelling as part of your day-today leadership practice?' and 'How and why do you use stories?'

The interviews varied in length from 30 to 90 minutes. Nearly all of the interviews were audio recorded and professionally transcribed. The exceptions to this were when we were grabbing an ad hoc chat in a bar or conference setting, or in the course of Author 2's day to day interactions with the group, when recording was impractical or inappropriate. On such occasions the researchers made notes and arrived at a shared understanding of the major points of conversations. The transcriptions of recordings ranged from 3,500 to 15,000 words amounting to a dataset of more than 450,000 words.

\section{[Table 1 here]}

\section{Data analysis}

Our data analysis is grounded on an appreciation that language is constitutive and central to how we construct social and organizational realities (Gabriel 2015). Our work examines one way in which chief executives try to influence these realities through their use of stories. We explored how chief executives create their local context through story and narrative techniques. Zooming in on chief executives' storytelling through their reflective accounts of their practices, our study took momentum from work which suggests that the constructive ways that language is used present important focal points for research (Grant, Keenoy and Oswick 1998; Reissner 2011). It is an approach based on an understanding that "local 
concepts and practices are where organizational structure and process come to life" (Agar 2010, 298).

The analysis of our transcripts and fieldnotes entailed standard, systematic, inductive and abductive processes in which we moved between data and theory focusing on instances of leadership and storytelling or narrative work. We identified explicit accounts of stories, sensemaking strategies, reflections on role, challenges and priorities for action, and how our respondents approach these challenges through stories and narratives. We also looked for other fragments of talk where leadership practices were to the fore or where their accounts said something important about leadership and storytelling. We used an open coding system in which iteratively we identified a raft of provisionally significant themes ("motivation", "managing complexity", "working across boundaries" etc.) which we then collapsed or combined into broader categories (Strauss and Corbin 1990). For example, data initially coded under category labels such as "ghost stories", "explaining complexity", "talking to professionals", were later assimilated under the broader thematic category sensemaking. We moved from data-generated first-order codes to second-order themes in keeping with the tradition and norms of interpretive research (Bevir and Rhodes 2015; Boyatzis 1998) and involving creative acts of interpretation. We sense-checked our interpretations with chief executives periodically through introducing some our developing thoughts within interview encounters, through email dialogues with interviewees in which we discussed what had emerged from engaging with their transcripts, through occasional practitioner pieces which we published in professional outlets and which initiated further responses from within that community as well as additional interview leads, and through many other conversations with members of this practitioner group. We represent our coding schema in Table 2. 


\section{[Table 2 here]}

\section{Stages of data collection and analysis}

Our research had multiple phases. These include 'being struck' by an interesting focal point for inquiry, the possibility of the co-authors collaborating on the project, an engagement with academic literature to sensitize us to what we might apprehend in the field (Blaikie 2000; Haverland and Yanow 2012), an initial selection of fifteen respondents to ascertain the feasibility of the research, and to 'test' our sense of the importance of the practice.

Thereafter, as we continued to develop the study, we used snowball sampling in which those interviewed suggested others, in a spirit appropriate to the idea of interlinked research conversations and which helped us think through whether the project was viable. However over time, and to reach beyond that network, this was combined with active purposive approaches to other participants to ensure inclusion of respondents from the spread of organizations, professional backgrounds, gender, level of experience, and so on. Interpretive research does not entail "random" or "perfectly controlled" respondent selection. Our strategy was to ensure "exposure" to multiple perspectives (Schwartz-Shea and Yanow 2012, $88)$.

Our early understandings of set piece storytelling (at conference bars to impress peers, or in formal meetings of assembled staff) gave way to new understandings of the range of ways in which storytelling and narrative practices are part of the day to day routines of chief executives. In light of new knowledge and insights garnered from the field interviews, our formulations and reformulations were subjected to further analysis in an "iterative, spiralcircular recursiveness of abductive reasoning" (Schwartz-Shea and Yanow 2012, 56). Our 
interpretive research was accomplished through an adaptive and recursive process in which inquiry, data generation and analysis are intertwined.

\section{Issues of access and positionality}

We were seeking to study an elite level of highly paid, powerful government managers. Because of the nature of their role they operate high levels of prioritization of their time and employ staff who control access accordingly. Access to that network was enabled by one of the researchers working for the early years of the project as an employee of that network. From its inception, our study design embraced the idea of academics (Author 1) and practitioners (Author 2) “coproducing” research knowledge. For a large part of the fieldwork process one of the authors, a practitioner, worked alongside council chief executives as director of their professional body, and the other author is a management school professor. Author 2 was 'in but not of' the world of chief executives, as senior member of their network though never having served as chief executive. Coproduction has been an inherent part of our research process and builds on the legacy of the early "pracademics" and the tradition of public administration as an inclusive field of study (Perry 2012; Posner 2009). Such collaborations promise a basis for generating knowledge for the benefit of both academics and practitioners. However, they involve the negotiation of different interests including those of the communities to which the co-researchers belong.

We were conscious of the political aspects of a process in which one of the researchers had particular professional connections and responsibilities to our group of participants which meant that we could not simply engage in 'hit and run' research but instead we understand access as an ongoing process (Feldman et al. 2003). Furthermore, with a sense of our responsibilities to the community of practice and the rhythms and protocols of interpretive research, we wished to avoid the "rush to diagnosis" that precludes the scope for concepts 
emerging in the field and foreshortens the opportunity to live with and muse upon the data (Haverland and Yanow 2012, 405). These procedures are the hallmarks of trustworthy and systematic interpretive research (Schwartz-Shea and Yanow 2012). We have also written peer-reviewed articles on our methods and the process of coproduction as opportunities to reflect and generate feedback on our experience of conducting the research and the dilemmas we encountered.

\section{Quality Control}

Interpretive research focuses on specific, situated meanings and meaning-making practices of actors and privileges local situated knowledge. Epistemologically we are seeking to understand practices from the perspective of everyday actors, which means that our sensemaking is contingent upon that of the actors themselves, who are therefore involved in the co-creation of interpretive understandings. Rigor or robustness in this tradition depends on our use of reflexivity and member-checking our emergent findings. We engaged in cross checking, or "self-monitoring" (Schwartz-Shea and Yanow 2012) of our interpretations at many stages - immediately after interviews while the encounter was still fresh in the mind, subsequent telephone conversations and email exchanges, and through taking stock of the emerging themes prior to subsequent interviews. The composition of the academicpractitioner team enabled us to bring to bear a scholarly eye as well as a perspective of someone closer to the chief executives' own milieu and everyday discourse and concerns, adding edge and nuance to our interpretive capacity. We also member-checked our interpretations through email exchanges and regular selection of respondents for follow up face to face discussion. In the next section we consider our interview data and set out the themes which emerged from our research conversations with the chief executives.

\section{Research Findings}


In line with the reporting canon of interpretive research and research on narratives (Bevir and Rhodes 2015; Miles, Huberman and Saldaña 2014; Saldaña 2016) we organize our findings in response to our research questions around four ways in which chief executives engage in storytelling and narrative practices within a network of relations. These are:

- Inviting an emotional connection with public service

- Making sense of organizational realities

- Provoking reflections on practices and assumptions

- Managing political relations with Council Leaders

As well as examples of stories and narrative work, our fieldwork examined practitioners' explanations of their practices. Our research allows us to show not just how chief executives use stories or try to influence narratives, it also allows us to explore why they do so. Our findings section therefore weaves in chief executives' reflections on their practices. Doing so enables us to foreground practitioners as analysts in their own right of leadership practices. We begin each thematic section with two vignettes to connect readers with the voices and stories of our participants, and to clearly establish stories as an object of study. This brings the idea of storytelling alive, and also enables us to distinguish storytelling from broader narrative practices.

\section{Inviting an emotional connection and commitment to public service}

\section{Dinghy}

People say local government doesn't have any power. I don't buy that. We have incredible power in the eyes of local people. I remember when the city flooded, the whole town center 
was under five feet of water. As chief executive I was out on a dinghy with three other council workers, with lifejackets and council badges. And a woman was hanging out her window in distress, with her crying baby. We pulled up below, and Andy who was at the front of the boat stood up and stretched up his arms and said 'It's OK, hand us your baby down.' And she did. The mother trusted us because we were from the council. That's the level of trust people give the council - that someone will hand over their baby to us. Don't underestimate the power and legitimacy of local government.

The opening vignette is a story Author 2 saw told by the chief executive - to his senior colleagues and, at other times, to new recruits in developmental sessions. It offers a rallying call, a reminder of the importance of their collective efforts. It shows the importance of council workers and invokes their special relationship with the public. The drama of the story - the rescue of a babe in arms - produces an emotional response and casts the role of local government in a warm light. It provides a counter point to any wider gloom about the esteem of councils. He has been worried that staff have developed an unhelpful sense of local government's diminishment as a public institution. The story is steeped in relational ideas: team work, relationships of trust, and the council's standing in the eyes of the public - even its $\log 0$ is a signifier of trustworthiness. Finally, it features a chief executive showing himself to be proud of working with others, on the front line, at a time of crisis.

Many of the chief executives identified the power that stories have to make amorphous concepts such as 'our customers' or 'the public' spring to life and appear more tangible. Our second vignette illustrates the point. It is a story one chief executive tells to staff when discussing the need to improve response times to enquiries and service requests.

\section{Granny}


I went round the building and said 'What are we going to try and do and why are we trying to do it?' And we talked about how many telephone calls get answered and all the rest, and I just told the story of my Grandmother. For a while, I lived with my Granny she used to put her rent money behind the curtain on the window sill and the rent man would come in and he would take it, and if my Gran had a problem - if the gate needed fixing or something - she would tell the rent man. My Gran never rang up the council - the rent man was from the council so why wouldn't he sort it out? He was the council's representative in her home. Absolutely right. And I was explaining to staff that I'd like to create the sort of organization where my Granny would be comfortable. Because we've all got this image of our grannies as being a little bit vulnerable but people who we cherish - 'Just imagine it's your Granny, think about it, design the service from her point of view'. So shortly after that we had Investors in People inspectors here and afterwards they said to me 'I'm sure you'll get the accreditation, it looks very good and, by the way, what's the story with your Granny? So many people have told me about your Granny!' And it's interesting that folks don't remember how many telephone calls they're getting, but they remember the story about the Granny. It reaches, it touches them.

His story makes the service user a more identifiable, intimate and vulnerable figure to whom almost any public servant would recognize the duty of providing support. His account also shows how stories can be replayed and retold and come to feature in the conversations of different actors, resonating through the organizational discourse. This example also suggests the way in which particular stories can serve as useful stock tales for a chief executive. Such stories have an enduring quality, conveying values and action-triggering emotion.

What do chief executives' reflections tell us about this practice? 
Our interviewees frequently highlighted that stories lend themselves to talking about the public mission of their organizations. Stories can be harnessed in the service of the mission. One chief executive explained the idea in this way: "The purpose is to win people over to altruism... connecting people with a higher purpose and giving them a sense that they're involved in a progressive enterprise - that it's not just a job, that actually they are making life better in a particular locality. I do use poetic license to try to win people over to a sort of collective cause." This chief executive accounts for his use of stories as being to evoke the moral purpose of the organization to move staff. He encourages managers to extend their horizons from their particular area of expertise, and to work in relation to the wider mission of the organization.

Likewise, another chief executive positions stories as creating an emotional and motivating connection: "Leadership requires storytelling - it requires empathy, it requires imagination and pictures and without that we can't manage people. We can get their compliance but we can't ever get their commitment... If you want to shift people's perceptions of what we're doing from cold control, facts, numbers, to warm influence, then you're going to need influence techniques like storytelling." His distinction between compliance and commitment suggests the difference between hierarchical authority and collaborative effort. For this practitioner, effective leadership entails others feeling aligned with the same aims. In large organizations, like local councils, chief executives cannot have a personal relationship with every member of staff. His explanation of his practice captures how stories allow chief executives to project empathy, to connect emotionally and to encourage commitment to shared goals in ways that traditional authority models cannot achieve. The underlying idea is that doing so can help frame the way different organizational members relate and can contribute to the public good. 


\section{Making sense of organizational realities}

Naked

I remember one Sunday morning I was in the changing rooms, totally exhausted, after a morning on the bike with the club. Just out the shower and my mobile rang. It was Tony Craddock [senior government figure and local MP]. I answered, stood there dripping wet. He told me what was on his mind... I spoke discreetly with him, as best I could, for a couple of minutes, assured him we'd deal with it. There I was, butt naked, everything hanging out. On the phone to the minister, surrounded by fifteen other guys from the club, from all walks of life, all getting changed and exchanging the usual banter. You've got to be ready for that kind of thing at any moment. This is the kind of organization we are.

We see the chief executive situated in 'off duty' bonding with cycling friends immersed in locker room chat and enjoying what he thinks will be some down time. Instead the story suggests how the chief executive is never out of contact and is in constant relation with key members of his professional network. The story invokes a sense of perpetual relationality. Through the telling of the tale he is encouraging colleagues - in this case his senior managers - to apprehend the idea of being exposed to others' expectations. The story shows the reach of the job. A chief executive is always 'switched on' and reachable, even when stripped, literally, of the day to day trappings of leadership. The story also communicates the idea of an organization which is accountable, scrutinized at the highest political levels, and which is expected to be able to act to fix things. The chief executive is framing an understanding of organizational realities - this is how it is.

Many interviewees also identified their role in influencing pan-organizational narratives. In other words, they see the importance of shaping how the council gets talked about, by staff or by others. A story can be deployed to support such wider narrative building. One interviewee 
shared a story which he regularly uses to illustrate the 'direction of travel' he wants his council to pursue, and the pride that staff should have in the organization. There had been a range of unfavorable narratives circulating about his organization. He explained that:

The message is I want staff to work in an organization they feel proud of, because that hasn't always been the case. When I first arrived in Scruffton in the eighties, there were apocryphal stories about how when asked at a party who you worked for, you just said 'I work in local government.' When you said what your profession was, you never mentioned the words Scruffton Council. So now I use a little story to illustrate what I was trying to get away from that once, early on in my career in Scruffton, we were sent off to some management center in the Home Counties. We were registering at the reception desks and the lady looked up and said, 'What's your name and where are you from?' I said 'My name's John Watson, Scruffton Council', and she said 'Oh I am sorry' - just as if I'd just reported a bereavement! It's that reaction from somebody behind a desk, saying 'Oh I'm so sorry to hear you work for Scruffton' - I thought that summed it all up.

This episode is used as a story in his everyday leadership practices to establish the low point of the council's reputation and provide a contrast to the ambition and worth he invites colleagues to develop. He told us: "I want us to be a well regarded authority that commands the respect of its citizens and I suppose that's my mission in life... Scruffton used to be something negative and we want to turn it into something that's more positive." He described his approach as constructing a narrative of confidence in the organization, signaling ambitious intentions, and preparing the ground for action. This example highlights how one leadership task can be displacing longstanding organizational narratives and establishing alternatives which can be generative of new practices. It shows how storytelling can work in support of that broader project. 
What do chief executives' reflections tell us about this practice?

The concept of the storytelling organization is firmly embedded in the chief executives' view of their role and setting. As one chief executive reflected, "Storytelling is enormously powerful. You cannot be a thoughtful leader of an organization without realizing how important it is, because when you ask people about the council, staff and councillors and residents will describe it in stories, not in philosophical constructs - we understand an organization through the stories that we tell." An implication of this insight is that leadership requires an ability to understand your relationship to the stories that others tell - to listen to them and engage with the worlds that they describe.

Or, as another reflected, "I'm very aware of the value of storytelling - in my current role you are required to sort of be the narrator in chief - both to the organization and to the wider world." In this case the chief executive sees himself not as the commander in chief at the top of the hierarchy, but the narrator in chief, someone who must lead through narrative. Narrative shapes organizational reality for those who 'look in from the outside' (taxpayers, regulators, those whose judgment is important), as well as for organizational members. He sees the importance of influencing the narrative - rather than relying on the power of hierarchy - as critical to his practice.

Our interviewees emphasized their leadership role in helping staff to interpret the turbulent environment of local councils, and providing meaning and focus for action. As one chief executive explained, stories communicate better and faster than other techniques. He analyzed this process as akin to selling or persuasion, and as a process of influencing people in the same direction, but one done in a time pressured environment: "A lot of what I have to do is make sense of things so staff don't get kind of buffeted by the winds that blow. We focus in on the things that are likely to be prevailing, whether that's local or national 
pressures... You have not much time to speak to lots of staff and you can only do that kind of sense making - 'what kind of journey we're on' - almost a selling job with staff - by telling a story, making a coherent narrative... to take people with you."

Many of our participants agreed on the power of stories to resonate more persuasively than other kinds of management data. As one put it: "How many times do you see a really good presentation of all the facts laid out before a committee, then one person comes along with a story, and it's gone? The story just undermines every single fact - the human-interest story just does it." Our respondents also reflected on how storytelling runs counter to other professional traditions which prize objectivity and rationality. One interviewee identified using stories partly stems from a critique of traditional management: "Professionalism requires one to be detached and factual and rational and all those things... In reality, to lead a group of people and get them engaged in something, you need to be a bit more than that." In reflecting on 'Making sense of organizational realities', our participants offered an appreciation that leadership involves positioning themselves in relation to others' stories.

\section{Provoking reflection on practices and assumptions}

Bench

I tell a story about customer service in this organization when I first arrived, about meeting a woman sitting on a bench crying, waiting to get in the building because it was shut from nine to ten o'clock because the staff were stressed - they'd done a staff survey. The fact that we sent out notices seeking house re-possession to people who'd got benefit applications in a tray for thirteen weeks was not considered a high enough priority for us to open our doors... I tell this story when I'm reminding people about why is it we do what we do - 'let's stay focused on our customer. 'But it's an event that moved me, that taught me something about where the business was at. It moved me and it taught me something - so I share that story 
because it might teach other people something. I think that's quite a different thing from describing what it will be like when we reach nirvana.

In this vignette the chief executive talked about the potential of stories to shift colleagues' understanding of their role and why working routines need to change. He offered the observation that such stories may not represent grand managerial visions. They may seem mundane and yet, for all that, they can be profoundly challenging of practices. The telling of this story is not a one off, but something that he does on a regular basis. The story has an unsettling purpose and he deploys it when the situation demands. It invites staff to question the extent to which their organizational practices privilege the workforce over the service users.

Participants offered many examples of their efforts to generate changes in their organizations, focusing on the reframing of practices and assumptions. In this second vignette, a County chief executive recounted her use of a story arising from her spell as head of a neighboring council, which had been in competition with her current authority for scarce government grant money. She framed one particular episode satirically to make a more general point to staff about the need to improve their approach to seeking external resources:

I was a District chief exec at the other end of the region and I used to love the County Council because they never turned up. So if you were bidding for money or trying to make a case, there was less competition... So I made a story out of necessity to 'up our game' by emphasizing how bad the perception of the County has been in the past. I based it on the experience of how much I enjoyed it - that's the story bit if you like - 'I used to love you lot because you never turned up and I got all the money!' See - overplay it that way to make the point that we now need to change, and we need to be in the right places - we need to be down at Whitehall and Westminster more often than we have been, using our elbows to get to the 
front of the queue, because we haven't done it in the past... So it's us as a story if you like... It rings bells and people understand... I illustrate it by standing there in Whitehall with my hands out.

The story is provocative: it presents an unflattering picture of her colleagues and challenges them to re-orient their practices towards seeking external resources. In this vignette we also see the chief executive deconstructing her own storytelling practice and talking about the importance of features such as narrative structure, exaggeration, and even some stage acting. It shows a chief executive portraying her changing relationship with staff - from being a vanquishing rival, forever able to scoop the pool, to a new but frustrated team mate exhorting her colleagues to greater efforts.

What do chief executives' reflections tell us about this practice?

One chief executive captured the dialogical nature of her interventions in re-framing professionals' understandings of their roles in the organization. She recalls a particular tension between managers of social services and the elected members whose policies were causing discontent amongst staff, based on a feeling that the service was being side-lined by the political executive. One of her strategies is to prime the Leader with a narrative to share with staff, inviting the Leader to connect his program with the priorities of the professionals. Her approach is to challenge the assumptions held by staff and, through that unsettling, begin to establish new appreciations of the organizational landscape, and the primacy of the politicians. She set out the example in this way: "Delivering social services - those staff involved think that's the most important thing in the world... Periodically we have to put the Leader in front of big groups of staff and get him to say how much he values social care: 'I care passionately about public service, I admire you all, you all do a difficult and important job, but my administration has particular priorities'. When staff can actually see somebody 
saying it and see they're obviously truthful and honest, then it's a bit easier for them... We have to keep talking them through it."

This example concerns narrative building rather than stories. It shows how the chief executive acts to mediate the relationship between the Council Leader and staff members. The approach endeavors to bring the politicians closer to the workforce. It suggests that narrative building involves an ongoing effort at maintaining and improving relations. This is perhaps especially challenging in a context where the political executive is understood by staff to be committed to reducing the number of employees.

Imbued in the stories that the chief executives often tell therefore is a desire to change the assumptions that underlie particular ways of practicing. Another chief executive offered a philosophical explanation of how he tries to re-shape the assumptions held by staff. He deconstructs opposing points of view, re-presents them, and offers an alternative, more in line with his own agenda: "I've always thought that to convince someone of anything you need probably to articulate their truth in a way which is probably better than they could. So you'll try and identify the truth of the other, whatever it is, articulate it for them and then say why it's wrong and why there's another truth that's better... But if you just say 'No, I believe in this, er... just follow me', you've got no chance. I think you've got to understand where people are at and you've got to try and articulate that and say why where they're at isn't good enough." He has no confidence in the traditional hierarchical model of leadership - you cannot just tell people what to do. Instead he describes his experience of putting himself in relation to others and of trying to generate a joint critique of practice and a shared way forward. His aim is for colleagues to agree with the need to change. But there is an appreciation that such a mutual understanding is an emergent process accomplished in a network of perspectives. Unsettling some assumptions along the way is seen as a necessary part of the job. 


\section{Managing political relations with Council Leaders}

Bishop

One simple one which I used a fortnight ago - we have a number of issues around equality and trying to move that agenda along in a council which hasn't given it a great deal of attention... It's very rural, very traditional... The issue was about LGBT rights. There was some resistance from some members... and this is a true story because it was about Christmas time I went up to see the Bishop. I went into his study, sat down, beautiful oldfashioned Georgian house, fantastic book-lined study, fire raging, you know... While he was waiting for a cup of tea he waved this bit of paper and said 'Look at this, look at this! Pages of it! Ten pages here - from one of my colleagues, a fellow Bishop, basically ranting about gay people.' And he said 'I don't know about you' he said, 'I don't think God cares what we do in the bedroom do you?' And it was just such a lovely line that I used that story with some of our politicians. It was a very good way of defusing what would have been a quite difficult discussion.

The story contains some classic elements - atmosphere, imagery, a theatrical central character - and is used as a resource to moderate the views of particular politicians, and to encourage them to move away from extreme policy positions. The story uses humor, and the authority of the Bishop, to achieve a softening up of hardline or unprogressive social attitudes.

A second vivid story about relations with politicians - one which he uses in staff development settings - is provided by another chief executive. He recounts the tale in order to demonstrate the subtle art of leadership influence:

Homer 
A senior Director and I wrote a book for a strategic planning series back in the day. We sent it to the publishers in February... In May the Conservatives won a majority, and this guy Homer, became Deputy Leader of the council and although he had very little formal education, he was a very astute guy. Harry and I decided we would try and get him interested in strategic matters because we knew that the Leader was a 'paper clip counter', there was no way that the Leader was going to have any understanding of anything strategic so we thought we'd work on the Deputy. So we started started feeding Homer ideas, involving him in discussions and he was a very quick learner. In July our book was published and we gave him a complimentary copy and he came back to us a few days later. He said he was 'very pleased to see that we'd picked up his ideas!' We'd sent it to the publishers in February, long before he was on the scene, but he genuinely believed that they were his ideas and that we'd used them in our book! I tell that as a story about how although visible leadership is very important, so is invisible leadership. Sometimes people will only be led if they think it was their idea in the first place.

The chief executive is developing the strategic awareness of the political leader through talk and reading. The story suggests how ideas emerge within a relational network and are coproduced by actors. At first glance Homer takes the chief executive's ideas and claims them as his own. A relational lens suggests that in the process of everyday conversations ('setting to work on Homer') the authorship and ownership of ideas becomes jointly assumed. Over time this episode became the basis of an instructional story that the chief executive shares to illustrate the complexity of that officer-member relationship to aid others' learning.

This relationship between elected politicians and administrators is regarded as a fundamental question in the study and practice of public administration (Nalbandian 2006; Svara 2006; Waldo 1980; Wilson 1887; Zhang and Feiock 2010). One chief executive described her role as a "buffer" between officers and members, and said an important part of her job is to 
translate one part of the organization to the other and to enable communication between officers and politicians. She often illustrates this highly relational idea to staff with an analogy: "I tell them to think of the council and the members as kind of two castles, linked by a drawbridge. My role is running up and down the drawbridge, interpreting one bit of the council to the other - because often members don't understand officers because they talk in professional speak, and officers don't understand the way members think. So I'm constantly interpreting one to the other and stopping the drawbridge being pulled up or attacked."

\section{What do chief executives' reflections tell us about this practice?}

In managing political relations with Council Leaders, the importance of wider organizational narratives comes to the fore in the chief executives' reflections. Interviewees emphasized the sensitivity of their role in relation to shaping narratives of change with local politicians. It is important that enabling the political storytelling is conducted behind the scenes, because of the need not to be seen to exceed his brief and encroach on the politicians' territory. Telling the story of the political journey must not usurp the role of the members. As one chief executive explains, "This is not something you want to be ostentatious about, but you're also 'doing the narrative' back to the politicians. When I arrived there was no habit of the chief exec going to political groups to talk about what the challenges were. And we've been doing a lot of that, going to group meetings, and the focus is the narrative - getting them to realize where they are, where they've been, where they're going."

In this reflection we see the chief executive talking about the importance and mechanics of influencing the political narrative. The process must be partly hidden from view, because to be too open about it would doom it to failure. Instead we hear how he goes to all the political group meetings, seeking to interpret and influence each narrative in parallel. He highlights the array of political narratives present. He identifies the project as building a wider account 
of the organization's direction, capacity and priorities. The account suggests how leadership is collective and emergent within the to-ing and fro-ing of organizational life. Political narratives are thus co-produced by a series of actors and networks in relation with each other.

Some chief executives were less coy about their role in this regard offering accounts of political management in which they have a more influential voice. Interviewees emphasized the importance of framing a narrative of change which makes connects with elected members and provides coherence to an otherwise diffuse set of policies, programs and decisions. Such reflections play up the role of officers in shaping political programs and the subsequent presentation of these. We see the role of the chief executive in ensuring coordination of the members. One chief executive explained the process in this way: "So we constructed a narrative about becoming the 'commissioning council'... as a means of delivering the members' transformation stuff and... engendering order - because it was chaotic... So we wrapped it all up into a coherent story and said to them, 'Isn't this what you're saying to us?... Right then here's a program, do you agree it?' I think it is their story - we just needed to help them construct a narrative."

In these accounts, chief executives emerge as co-authors, sounding boards, co-developers of strategy, challengers and co-interpreters of political vision. They are therefore redolent of what Demir and Nyhan (2008) call politically active public administrators, adding value to democratic processes through purposive use of narrative in relation to political guidance and policy leadership. One key to understanding the relationship is the formal boundaries between officers and elected members and how these roles are interpreted on an everyday basis. Chief executives are not political appointees and therefore have a certain independence of any Leader. Yet there is a requirement to facilitate local representative democracy. The relationship between chief executive and politician is formal. But they are not standardized and depend greatly on personalities, cultures and competences. These complex relationships 
are interdependent, not binary. There are important protocols but there is a lot of un-ruled territory where evolving relationships of custom and practice reign. Our data is therefore linked to the politics-administration issue. However, it more closely concerns the personal relationships between chief executive and Leader. Specifically, it shows how chief executives engage in an array of narrative work and storytelling to manage these interactions.

\section{Discussion and Conclusion}

Our study contributes to interest in how leadership is produced and performed in context. We have applied insights of relationality to storytelling and narrative practices of local government chief executives. We examined specific stories (the vignettes) as well as considering broader narrative work (such as political narratives). We analyzed the role and relevance of storytelling and narrative as leadership practices that public administrators use to enact leadership in complex environments. Relationality scholarship highlights the importance of stories and narratives as a basis for researching the collective dimensions of leadership. Relationality requires finding ways to view “...the invisible threads that connect actors engaged in leadership processes" (Uhl-Bien and Ospina 2012, 23). Stories and narratives provide an excellent starting point.

The research findings explored examples of storytelling and narrative practices (the how) and the reasons public administrators have for taking an active interest them (the why). The section included chief executives' reflections on their practices. We identified different roles stories and narratives play in the contemporary public management repertoire. Our four thematic categories are grounded in a relational ontology, and Uhl-Bien and Ospina's (2012) encouragement to focus on collective aspects of organizational action.

Across all four themes a challenge was finding a terminology to describe analytical categories which embrace relationality and yet which allow for individual agency. A 
relational approach enshrines a self/other dynamic (and therefore the idea that leadership is accomplished in "the spaces between") and does not lend itself to category labels which imply the unbounded influence of particular individuals, or which lapse into heroic models of leadership.

The first category - Inviting an emotional connection and commitment to public service - is highly relational. Storytelling enables chief executives to propose a re-casting of relationships with the public, and a re-alignment between colleagues in different parts of the organization. This can be approached through connecting staff to what Perry and Hondeghem (2008) describe as "the Call of Public Service". Such storytelling aims to produce an emotional response among diverse employees.

Our second thematic category - Making sense of organizational realities - analyzes how a collective sense of the organizational landscape is constructed. Within a network of relations, chief executives engage in storytelling with the aim of co-interpreting a changing environment, raising awareness of the significance of others' expectations, or mobilizing action. An aspect of relationality here is that they must do so in the face of competing narratives and interpretations.

The third - Provoking reflection on practices and assumptions - perhaps suggests a more pronounced picture of chief executives' agency within their networks. The stories are explicitly interventionist and challenging, unsettling colleagues' everyday professional routines. Or, they try to change the assumptions about practices. The stories offer critique and aim to generate change, but their tellers anticipate a skeptical audience.

The fourth category - Managing political relations with Council Leaders - concerns a particularly important dimension of the chief executives' work - their relationship with politicians. Our data shows how practitioners use terms like "political storytelling" and 
"constructing the narrative" interchangeably. Through a relational lens we analyze the role narrative practices play in managing this critical officer-member relationship. It demonstrates how chief executives manage interactions to help Leaders get what they need, and ensure that the collective is not vulnerable to a lack of political discipline. It accentuates that political narratives, policy making and strategy formation are co-produced.

This research helps us appreciate the complexity of the chief executive role in a number of significant ways. While political organizations have always been a rich fund of colorful stories (who's up, who's down, who's in, who's out) and powerful visions (of a brighter tomorrow), storytelling has been largely absent from accounts of managerial leadership in public administration. Our research highlights ways in which storytelling- and the broader idea of narrative - represents a significant part of their everyday relational leadership practices. If collective leadership requires visioning (Ospina and Foldy 2015) then, in our study, stories emerge as a facilitative resource, inviting others to contribute to how the present is understood and the future is imagined.

Wright, Moynihan and Pandey (2012) position transformational leaders as a source of idealized influence. On one reading, our vignettes provide examples of how influence is pursued through the thoughtful use of stories. However, our analysis and theorizing offers a relational understanding of these practices, and provides a more circumscribed view of the agency of individual leaders, eschewing a heroic or transformational perspective. Mainstream understandings of leadership continue to influence leadership training and practice. A conceptualisation of leadership as collective implies a need for changes to leadership training. In this respect, our study contributes to an understanding of practices underpinning distributed forms of leadership.

\section{Limitations}


How can we be sure that our research participants tell stories? Or, that they are not simply presenting stories to impress the researchers? As interpretive researchers we are not “captives' of what we have been told by our respondents (Schwartz-Shea and Yanow 2012, 112). We accept the idea of partial knowledge and multiple perspectives. We have tried to address this by sensechecking between members of the research team, reading our interviews in the context of our own wider interactions with chief executives, and having reflexive dialogues with our participants as we developed our analysis. Though we have explored the setting through the lens of relationality we accept that there are absences and silences. Interpretive research does not entail perfectly controlled data selection. We have endeavoured to ensure exposure to multiple perspectives and, following Gabriel $(1998,12)$, we have chosen stories which were "good enough to bear repetition... [and] capable of yielding telling and fruitful interpretations."

The question of what is a story and what is a narrative is a longstanding controversy. We found Feldman et al.'s (2004) of their interrelationship to be a useful working definition. We also note that practitioners tend to use the terms interchangeably in ways which suggest a pleasing 'relationality' appropriate to this study. Nonetheless in our Findings we have been careful to identify stories (presented as vignettes) and wider narrative building.

How do we know if these storytelling and narrative practices had impacts? We agree with Boje (2008) that stories can help change organizational relationships, but tracking impact was beyond the scope of our study. More fundamentally, in our relational analysis we present story and narrative activity as ongoing interactive practices, rather than completed projects with unified meaning and consequences. At minimum we show how they draw aspects of the work of the organization into the sphere of dialogue.

\section{Final thoughts}


An emphasis on collective leadership does not dissolve hierarchy or power relations (Denis, Langley and Sergi 2012). Shared values are necessary for collective leadership to flourish. However, this undertaking is "politically charged" (Alvesson and Sveningsson 2012, 215). Organizations are sites of struggle filled with competing voices. Actors may adapt their understandings or espouse new values without feeling committed to them. Our future research will look at other parts of local government, examining narratives and change at the front line.

The idea that stories are part of organizational life is not new, though it is under explored in public administration. Narratives and stories emerge as expressive aspects of leadership practice. Our focus on relationality highlights that chief executives are not in positions of hierarchical control over the discursive domain. Stories fulfill wider roles as part of the timeless dynamic of everyday social encounters. A multitude of stories and storytellers are at large at any one time. Organizations are not populated by unthinking obedient automatons, and storytelling as an exercise in framing meaning does not take place in the face of uncritical, passive recipients. Chief executives would agree with the characterization of their organizations as spaces teeming with politics, skepticism, and competing values - they are polyphonic settings in which alternative stories and interpretations vie for resonance and credibility. Leadership in public administration emerges from relational zones of ambiguity, opposition, agreement, shared commitment and discord. Exploring stories and narratives provides a rich picture of public administration leaders pursuing influence of organizational relationships and realities.

\section{References}


Agar, Michael. 2010. On the Ethnographic Part of the Mix. A Multi-Genre Tale of the Field. Organizational Research Methods 13(2): 296-303.

Alvesson, Matts. 2003. Beyond Neo-Positivism and Localism. A Reflective Approach. Academy of Management Review 28(1): 13-33.

Bains, M. (Chairman). 1972. The New Local Authorities: Management and Structure. London: HMSO.

Barthes, Roland. 1977. Image Music Text. (Trans. Stephen Heath). London: Fontana Press.

Bevir, Mark. 2011. Public Administration as Storytelling. Public Administration 89(1): 183195.

Bevir, Mark and R.A.W. Rhodes, eds. 2015. Routledge Handbook of Interpretive Political Science. New York: Routledge.

Blaikie, Norman. 2000. Designing Social Research: The Logic of Anticipation. Malden MA: Polity Press.

Boje, David M. 1991. The Storytelling Organization: A Study of Storytelling Performance in an Office Supply Firm. Administrative Science Quarterly 36: 106-126.

Boje, David M. 2008. Storytelling Organizations. London: SAGE.

Borins, Stanford. 2011. Making Narrative Count: A Narratological Approach to Public Management Innovation. Journal of Public Administration Research and Theory. 22: 165-189.

Boyatzis, R.E. 1998. Transforming Qualitative Information: Thematic Analysis and Code Development. Thousand Oaks, CA: Sage.

Brown, Andrew, Yiannis Gabriel and Silvia Gherardi. 2009. Storytelling and Change: An Unfolding Story. Organization 16(3): 1350-5084.

Brown, Andrew, Patrick Stacey and Joe Nanhakumar. 2008. Making Sense of Sensemaking Narratives. Human Relations 61(8): 1035-1062.

Clark, B.R. 1972. The Organizational Saga in Higher Education. Administrative Science Quarterly 17:178-184.

Cooper, Robert and Gibson Burrell. 1988. Modernism, Postmodernism and Organizational Analysis: An Introduction. Organization Studies 9(1): 91-112.

Crevani, Lucia, Monica Lindgren and Johann Packendorff. 2010. Leadership, Not Leaders: On the Study of Leadership as Practices and Interactions. Scandinavian Journal of Management. 26, 77-86.

Czarniawska, Barbara. 1998. A Narrative Approach to Organization Studies. London: SAGE. 
Dachler, H. Peter. 1992. Management and Leadership as Relational Phenomena. In Mario von Cranach, Willem Doise and Gabriel Mugny (Eds.), Social Representations and Social Bases of Knowledge (169-178). New York: Hogrefe and Huber.

Demir, Tansu and Ronald C. Nyhan. 2008. The Politics-Administration Dichotomy: An Empirical Search for Correspondence Between Theory and Practice. Public Administration Review 68(1): 81-96.

Denis, Jean-Louis, Ann Langley and Viviane Sergi. 2012. Leadership in the Plural. The Academy of Management Annals. 6(1): 211-283.

Fairhurst, Gail T. 2007. Discursive Leadership. In Conversation With Leadership Psychology. London: Sage.

Fairhurst, Gail T. and Mary Uhl-Bien. 2012. Organizational Discourse Analysis (ODA): Examining Leadership as a Relational Process. The Leadership Quarterly 23(6): 10431062.

Feldman, Martha S., Jeannine Bell, and Michele Tracy Berger, eds. 2003. Gaining Access. Walnut Creek, CA: AltaMira.

Feldman, Martha S., Anne Khademian, and Kathryn S. Quick. 2009. Ways of Knowing: Inclusive Management and Promoting Democratic Engagement. International Public Management Journal 12(2): 123-136.

Feldman, Martha S., Kai Skoldberg, Ruth Nicole Brown, and Debra Horner. 2004. Making Sense of Stories: A Rhetorical Approach to Narrative Analysis. Journal of Public Administration Research and Theory 14(2): 147-170.

Feldman, Steven P. 1990. Stories as Cultural Creativity: On the Relationship Between Symbolism and Politics in Organizational Change. Human Relations 43(9): 809-828.

Fischer, Frank. 2003. Reframing Public Policy: Discursive Polities and Deliberative Practices. Oxford: Oxford University Press.

Fletcher, Joyce K. 2004. The Paradox of Post-Heroic Leadership: An Essay on Gender, Power, and Transformational Change. The Leadership Quarterly. 15(5): 647-661.

Gabriel, Yiannis, ed. 2004. Myths, Stories and Organizations: Premodern Narratives for Our Times. Oxford: Oxford University Press.

Gabriel, Yiannis. 2015. Storytelling. In Mark Bevir and R.A.W. Rhodes, eds. Routledge Handbook of Interpretive Political Science. New York: Routledge.

Gold, Jeff. 1997. Learning and Storytelling: The Next Stage in the Journey for the Learning Organization. Journal of Workplace Learning 9(4): 133-145. 
Grant, David, Tom Keenoy, and Cliff Oswick. 1998. Discourse and Organization Studies. London: Sage.

Hampton, Greg. 2009. Narrative Policy Analysis and the Integration of Public Involvement in Decision Making. Policy Sciences 42: 227-242.

Haverland, Markus and Dvora Yanow. 2012. A Hitchhiker's Guide to the Public Administration Research Universe: Surviving Conversations on Methodology and Methods. Public Administration Review 72(3): 401-408.

Herman, David, ed. 2007. The Cambridge Companion to Narrative. Cambridge: Cambridge University Press.

Hummel, Ralph P. 1991. Stories Managers Tell: Why They Are as Valid as Science. Public Administration Review 51(1): 31-41.

Kanter, Rosabeth Moss. 1977. Men and Women of the Corporation. New York: Basic Books.

Kellerman, Barbara, and Scott W. Webster. 2001. The Recent Literature on Public Leadership Reviewed and Considered. The Leadership Quarterly 12: 485-514.

Kouzes, James M. and Barry Z. Posner. 2002. The Leadership Challenge. San Francisco: John Wiley and Sons.

Lejano, Raul P. and Ching Leong. 2012. A Hermeneutic Approach to Explaining and Understanding Public Controversies. Journal of Public Administration Research and Theory 22(4): 793-814.

Maclean, Mairi, Charles Harvey and Robert Chia. 2013. Sensemaking, Storytelling and the Legitimization of Elite Business Careers. Human Relations 65(1): 17-40.

Maynard-Moody, Steven and Michael Musheno. 2003. Cops, Teachers, Counselors. Stories from the Front Lines of Public Service. Ann Arbor: University of Michigan Press.

McConkie, Mark L. and Wayne Boss. 1986. Organizational Stories: One Means of Moving the Informal Organization During Change Efforts. Public Administration Quarterly 10: 189-205.

Miles, Matthew B., Huberman, A. Michael and Johnny Saldaña. 2014. Qualitative Data Analysis. A Methods Sourcebook. Third Edition. Los Angeles: Sage.

Mintzberg, Henry. 1973. The Nature of Managerial Work. New York: Harper and Row.

Mitroff, Ian I. and Ralph H. Kilmann. 1975. Stories Managers Tell: A New Tool for Organizational Problem Solving. Management Review July: 18-22.

Moore, Mark H. 1995. Creating Public Value. Cambridge Massachusetts: Harvard University Press. 
Nalbandian, John, Robert O’Neill, Jr., J. Michael Wilkes, and Amanda Kaufman. 2013. Contemporary Challenges in Local Government: Evolving Roles and Responsibilities, Structures, and Processes. 2013. Public Administration Review 73(4): 567-574.

Nalbandian, John. 2006. Politics and Administration in Local Government. International Journal of Public Administration 29(12): 1049-1063.

Ng, Wilson and Christian De Cock. 2002. Journal of Management Studies 39(1): 23-49.

Ospina, Sonia M., and Jennifer Dodge. 2005. It's About Time: Catching Method Up to Meaning: The Usefulness of Narrative Inquiry in Public Administration Research. Public Administration Review 65(2): 143-157.

Ospina, Sonia M. and Erica Gabrielle Foldy. 2010. Building Bridges from the Margins: The Work of Leadership in Social Change Organizations. The Leadership Quarterly. 21(2): 292-307.

Ospina, Sonia M. and Erica Gabrielle Foldy. 2015. Enacting Collective Leadership in a Shared-Power World. In James L. Perry and Robert K. Christensen (Eds.), Handbook of Public Administration. Third Edition. San Francisco: Wiley.

Perry, James L. 2012. How Can We improve Our Science to Generate More Usable Knowledge for Public Professionals? Public Administration Review 72(4): 479-482.

Perry, James L. and Annie Hondeghem, eds. 2008. Motivation in Public Management: The Call of Public Service. New York: Oxford University Press.

Posner, Paul L. 2009. The Pracademic: An Agenda For Re-Engaging Practitioners and Academics. Public Budgeting \& Finance 29:12-26.

Raadschelders, Jos C. N. and Kwang-Hoon Lee. 2011. Trends in the Study of Public Administration. Public Administration Review 71(1): 19-33.

Rabinow, Paul and William M. Sullivan, eds. 1987. Interpretive Social Science: A Second Look. Berkeley: University of California Press.

Reissner, S.C. 2011. Patterns of Stories of Organisational Change. Journal of Organizational Change Management 24(5): 593-609.

Rhodes, Carl and Andrew Brown. 2005. Narrative, Organizations and Research. International Journal of Management Reviews 7(3): 167-188.

Ricoeur, P. 1984. Time and Narrative, 1. Chicago: University of Chicago Press.

Saldaña, Johnny. 2016. The Coding Manual for Qualitative Researchers. Los Angeles: Sage.

Schram, Sanford F. and Philip T. Neisser, eds. 1997. Tales of the State: Narrative in Contemporary U.S. Politics and Public Policy. Lanham: Rowman and Littlefield. 
Schwartz-Shea, Peregrine and Dvora Yanow. 2012. Interpretive Research Design. New York: Routledge.

Skoldberg, Kai. 1994. Tales of Change: Public Administration Reform and Narrative Mode. Organization Science 5(2): 219-238.

Spillane, James P. 2006. Distributed Leadership. San Francisco: Jossey-Bass.

Society of Local Authority Chief Executives (SOLACE). 2014. Submission to Communities and Local Government Select Committee Inquiry Into Local Government Chief Officer Remuneration. London: SOLACE.

Sternberg, Robert J. 2008. The WICS Approach to Leadership: Stories of Leadership and the Structures and Processes that Support Them. The Leadership Quarterly 19: 360-371.

Stillman, Richard J., II. 2011. Why PAR Matters: Reflections after Seven Decades and Beyond. Public Administration Review 71(6): 909-915.

Strauss, Anselm, and Juliet Corbin. 1990. Basics of Qualitative Research. Thousand Oaks, C.A.: Sage.

Svara, James H. 2006. Introduction: Politicians and Administrators in the Political Process A Review of Themes and Issues in the Literature. International Journal of Public Administration 29: 953-976.

Taylor, Steven S., Dalmar Fisher and Ronald L. Dufresne. 2002. The Aesthetics of Management Storytelling: A Key to Organizational Learning. Management Learning 33(3): 313-321.

Trottier, Tracey, Montgomery Van Wart, and XiaoHu Wang. 2008. Examining the Nature and Significance of Leadership in Government Organizations. Public Administration Review 68(2): 319-333.

Uhl-Bien, Mary. 2006. Relational Leadership Theory: Exploring the Social Processes of Leadership and Organizing. The Leadership Quarterly. 17: 654-676.

Uhl-Bien, Mary and Sonia M. Ospina, eds. 2012. Advancing Relational Leadership. A Dialogue Among Perspectives. Charlotte, NC: Information Age Publishing.

Van Wart, Montgomery. 2003. Public Sector Leadership Theory: An Assessment. Public Administration Review 63(2): 214-228.

Van Wart, Montgomery. 2013. Lessons from Leadership Theory and the Contemporary Challenges of Leaders. Public Administration Review 73(4): 553-565.

Vance, C.M. 1991. Formalizing Storytelling in Organizations: A Key Agenda for the Design of Training. Journal of Organizational Change Management 4: 52-58. 
Wagenaar, Hendrik. 2004. "Knowing" the Rules: Administrative Work as Practice. Public Administration Review 64(6): 643-656.

Waldo, Dwight. 1968. The Novelist on Organization and Administration: An Inquiry Into the Relationship Between Two Worlds. Berkeley: University of California.

Waldo, Dwight. 1980. The Enterprise of Public Administration: A Summary View. Novato CA: Chandler \& Sharp.

Weick, Karl E. 1995. Sensemaking in Organizations. London: SAGE.

Wilkins, Alan 1984. The Creation of Company Cultures. Human Resource Management 23: 41-60.

Wilson, Woodrow. 1887. The Study of Administration. Political Science Quarterly 2(2): 197-222.

Wright, Bradley E., Donald P. Moynihan and Sanjay K. Pandey. 2012. Pulling the Levers: Transformational Leadership, Public Service Motivation and Mission Valence. Public Administration Review 72(2): 206-215.

Yanow, Dvora and Peregrine Schwartz-Shea, eds. 2014. Interpretation and Method. Empirical Research and the Interpretive Turn. Second edition. New York: M.E. Sharpe.

Yukl, Gary A. 2006. Leadership in Organizations (6 ${ }^{\text {th }}$ edition). NJ: Prentice Hall.

Zhang, Yahong and Richard C. Feiock. 2010. City Managers' Policy Leadership in CouncilManager Cities. Journal of Public Administration Research and Theory 20(2): 461-476. 
Table 1: Data exposure

\begin{tabular}{|l|l|}
\hline Type of UK Council & Number of chief executives interviewed \\
\hline Unitary authorities & 21 \\
\hline County councils & 7 \\
\hline District councils & 24 \\
\hline London boroughs & 15 \\
\hline Metropolitan/city councils & 13 \\
\hline
\end{tabular}


Table 2: Coding and themes

Importance of councils; Distinctive mission; Storying of making a difference; Vulnerable people; Public trust; Legitimacy; Reputation; Duties; Public good; 'Warm influence';

Beyond control; Gaining commitment; Emotional response; Connecting on a personal level; Bringing abstractions to life; Safety net; Democracy purposes; Values; Organizational
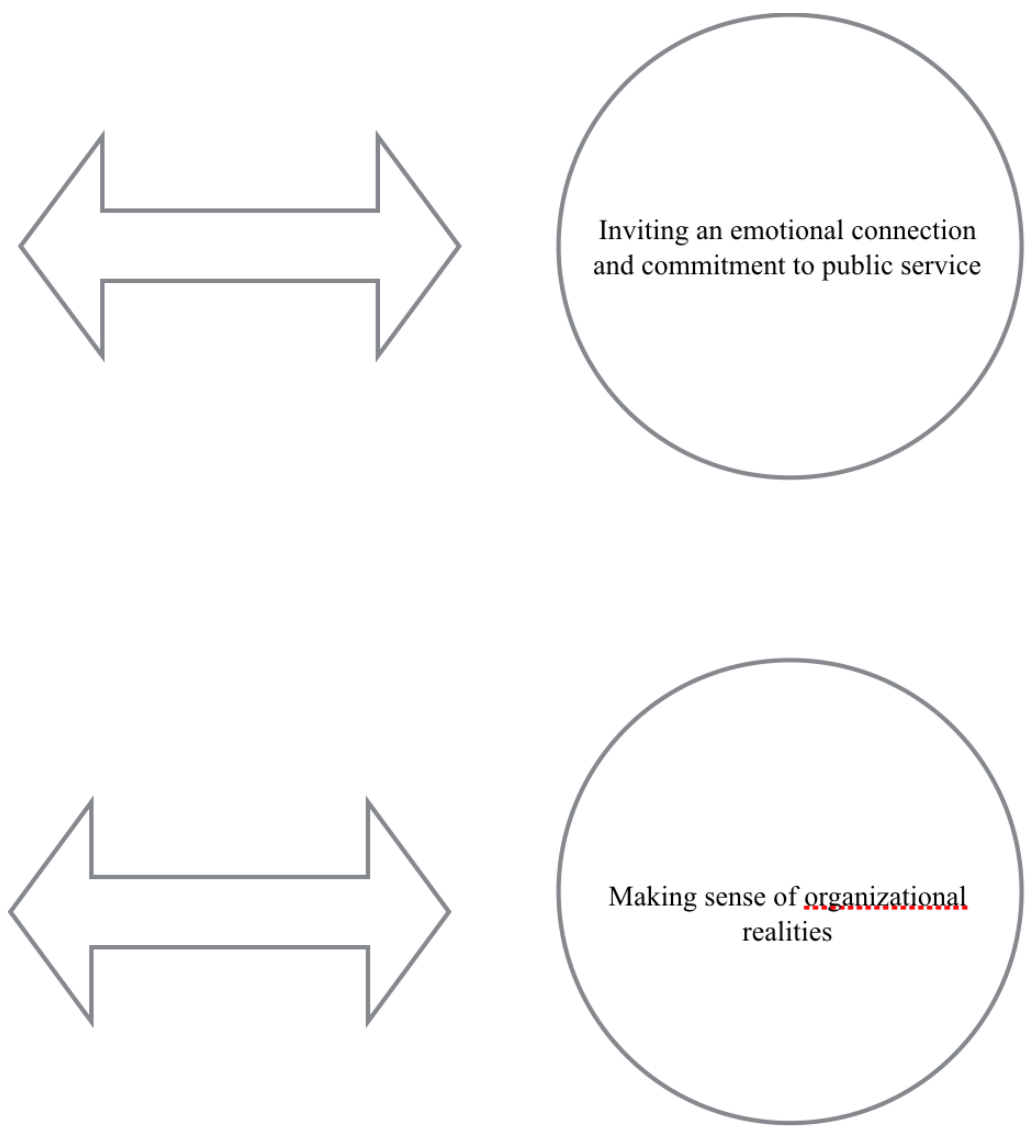

Talking about councillors; Internal communications; Illustrating direction of travel

Talking to professionals; Framing change to front line staff; Storying of change; Broadening perspectives; Working across boundaries; Connecting groups; Creating common cause; Managing complexity;

Managing corporacy; Establishing reference points; Reminding staff of the role of politicians; Explaining the financial environment; Policy talk; 'Narrator in chief'; Interpreting the environment; Mapping external change; Managing expectations;

Talking about budgetary constraints;

Unsettling; Challenging status quo; Making case for change;

Storying failure; Motivation;

Reframing assumptions; Storying poor performance; Stories of reflection; Transforming practice;

Ghost stories; Leadership of change; Explaining need to change priorities; Self-challenge;

Questioning practices; Deficiencies;

Envisioning alternatives

Influencing politicians; Connecting politicians; Storying the political message; Conversations with Leader; Confidentiality; Political narrative; Sounding board; Political advice; Storying of political programs; Political management; Interpreting the vision; Reconciling political objectives with capacity; Roles; Briefings; Officermember relations; Primacy of members; Managing the members
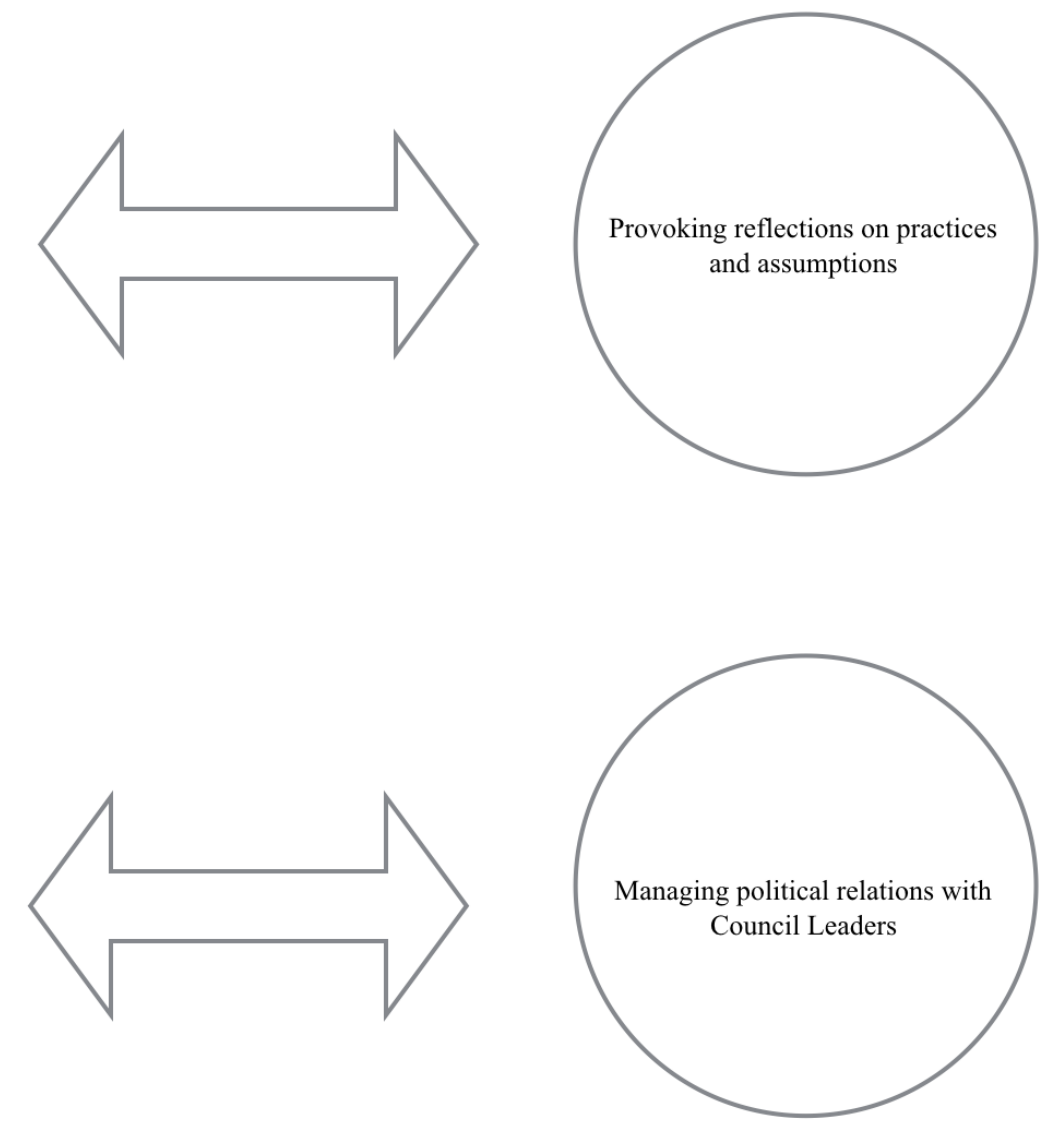